\title{
Effect of Formic Acid Surface Modification on Bond Strength of Solid-State Bonded Interface of Tin and Copper
}

\author{
Shinji Koyama, Yukinari Aoki* and Ikuo Shohji \\ Graduate School of Engineering, Gunma University, Kiryu 376-8515, Japan
}

The effect of formic-acid surface modification on the bond strength of the solid-state bonded interface of tin and copper has been investigated by SEM observation of the interfacial microstructures and fractured surfaces. Formic-acid surface modification was carried out by boiling a tin and a copper surface in formic acid for $600 \mathrm{~s}$. Solid-state bonding was carried out in a vacuum chamber at a bonding temperature $T$ of $403-473 \mathrm{~K}$ and a bonding pressure $P$ of $7 \mathrm{MPa}$ (bonding time: $t=1800 \mathrm{~s}$ ). The bond strength increased with an increase in the bonding temperature, independently of the formic-acid surface modification. Because of the surface modification, bonded joints were obtained at a bonding temperature that was $40 \mathrm{~K}$ less than the typical temperature required, and the bond strength was comparable to that of the base metal. When surface modification is applied, the oxide film is destroyed by the improved plastic deformability of the tin. Thus, the tensile strength of the joint is increased. On the other hand, when surface modification is applied, a high-tensile-strength joint is obtained at a low temperature because metallic tin and copper are exposed at the bond interface as a result of the decomposition of formate in the bond interface at a low temperature. [doi:10.2320/matertrans.MJ201019]

(Received April 13, 2010; Accepted August 3, 2010; Published September 15, 2010)

Keywords: tin, copper, bonding, interface, strength, surface modification, formic acid

\section{Introduction}

We propose mounting electronic parts using solid-state bonding rather than the fusion bonding method; this technology is suitable for miniaturized electronic equipment. Two methods have been discussed in the literature: (1) bonding after the oxide film of the bond interface has been removed by supersonic wave vibration ${ }^{1-4)}$ and (2) bonding after the bond surface has been cleaned by plasma processing. ${ }^{5-8)}$ Parts that are sensitive to heat and have a low mechanical strength, such as optical parts and microsensors, are now used multiple times. An economical method to obtain a high-strength joint at a low temperature and load is required. Earlier research showed that surface modification with formic acid decreased the bonding temperature required to obtain a high-bond-strength joint in the solid-state bonding of tin. ${ }^{9)}$ Therefore, in this investigation we aimed to obtain a deeper understanding of the effect of surface modification on the performance of a solid-state bonded joint of tin and copper. We used a scanning electron microscope (SEM) to observe the bonded interfaces and the fractured surfaces.

\section{Experimental Details}

The specimen to be bonded was a block of dimensions $15 \times 15 \times 5 \mathrm{~mm}^{3}$ cut from a $99.9 \%$ tin ingot. This tin block was bonded to a copper block for the convenience of the tensile test of the joint (see Fig. 1). The copper specimen was cut from a $99.8 \%$ copper ingot. The faying surface of the tin $\left(15 \times 15 \mathrm{~mm}^{2}\right.$ face $)$ was finished by electrolytic polishing in a solution containing $5 \%$ perchloric acid in $10 \%$ ethyl glycol monobutyl and $85 \%$ ethyl alcohol. The surface roughness $R_{\mathrm{a}}$ was $0.33 \mu \mathrm{m}$. The faying surface of the copper $\left(15 \times 15 \mathrm{~mm}^{2}\right.$ face) was finished by grinding on emery paper of grade 4000 . The surface roughness $R_{\mathrm{a}}$ was $0.07 \mu \mathrm{m}$.

*Graduate Student, Gunma University

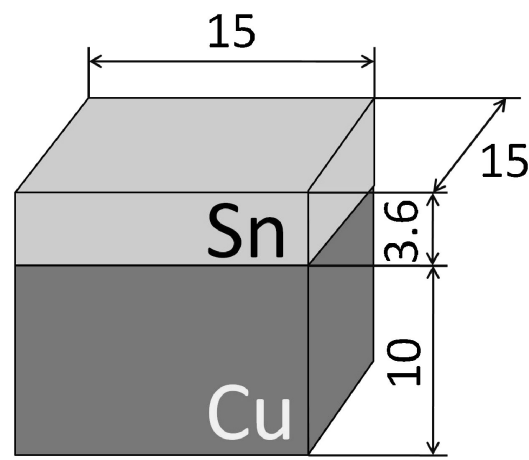

Fig. 1 Schematic illustration of specimen to be bonded (in $\mathrm{mm}$ ).

Formic-acid surface modification was carried out by boiling a tin and a copper surface in formic acid for 300$900 \mathrm{~s}$. To determine the compound formed on the surface after the surface modification, the tin and copper surfaces were investigated using an X-ray diffractometer (XRD) with $\mathrm{CuK} \alpha$ radiation working at the optimum voltage of $32 \mathrm{kV}$ and anodic current of $20 \mathrm{~mA}$. After surface modification, the specimen was placed in a vacuum chamber within $180 \mathrm{~s}$ to avoid oxidation or moisture absorption of the surfaces. The solid-state bonding was carried out in the vacuum chamber at bonding temperatures $T$ from 403 to $473 \mathrm{~K}$. The bonding pressure $P$ and the bonding time $t$ were fixed at $7 \mathrm{MPa}$ and $1.8 \mathrm{ks}$, respectively. After the solid-state bonding, the specimen was cut into three pieces for the tensile test and observation of the interface. For the metallographic observation, the surfaces (transverse section) were ground and polished and then inspected with an SEM. The bond strength was estimated from the tensile strength of the joint. The specimen for the tensile test was cut from a bonded joint to give a sectional area of $3 \times 3 \mathrm{~mm}^{2}$. The tensile test was carried out in the vertical direction of the bonded interface at room temperature and a displacement speed of $0.017 \mathrm{~mm} / \mathrm{s}$. 


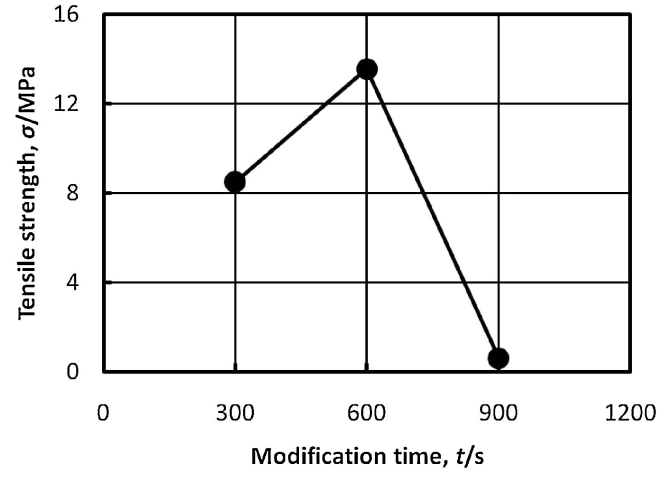

Fig. 2 Relationship between tensile strength and modification time.
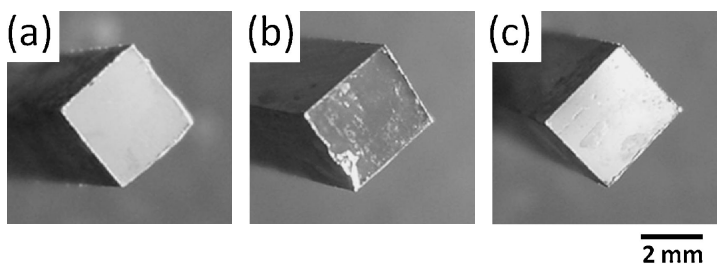

Fig. 3 Optical macroscopic images of fractured surfaces of joints after tensile test: (a) $t=300 \mathrm{~s}$, (b) $t=600 \mathrm{~s}$, and (c) $t=900 \mathrm{~s}$.
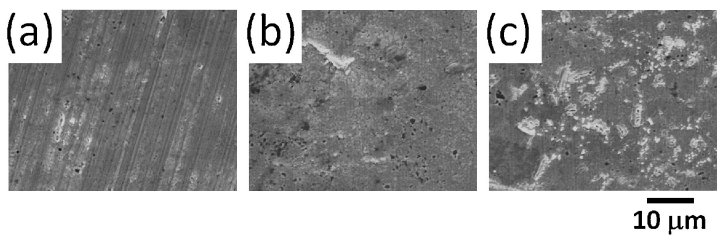

Fig. 4 SEM micrographs of fractured surfaces of joints after tensile test: (a) $t=300 \mathrm{~s}$, (b) $t=600 \mathrm{~s}$, and (c) $t=900 \mathrm{~s}$.

\section{Experimental Results}

\subsection{Effect of surface modification on the bond strength}

To examine the influence of the surface-modification time on the tensile strength of the joint, the solid-state bonding was carried out at modification times $t$ from $300-900 \mathrm{~s}$ and the bonding temperature $T$ was fixed at $413 \mathrm{~K}$. The relationship between the modification time and the tensile strength of the joints is shown in Fig. 2, and optical macroscopic images of the fractured surfaces of the copper side of the joints after the tensile test are shown in Fig. 3. The joint with the highest strength was obtained when the modification time was $600 \mathrm{~s}$. When the modification time was $300 \mathrm{~s}$, the surface was copper-colored; when the time was $600 \mathrm{~s}$, signs of tin adhering to the surface of the copper were observed; and when the time was $900 \mathrm{~s}$, the surface was white.

It is thought that the occurrence of breaks at the interface causes the insufficient or excessive modification time. To verify this, the fractured surfaces of the copper side of these joints were observed by SEM. When the modification time was $300 \mathrm{~s}$, as shown in Fig. 4(a), polishing flaws were observed and brittle fractures appeared although signs of tin adhering to part of the area were observed. When the modification time was $900 \mathrm{~s}$, as shown in Fig. 4(c), no

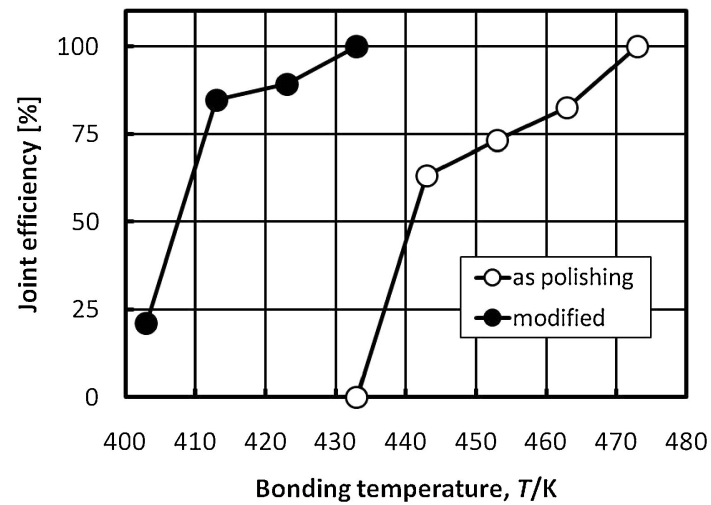

Fig. 5 Effect of surface modification on relationship between strength of joint and bonding temperature. Bonding pressure and time for all joints were $7 \mathrm{MPa}$ and $1.8 \mathrm{ks}$ respectively.

polishing flaws were observed and there were numerous white particles of $1 \mu \mathrm{m}$ or less in diameter. On the other hand, when the modification time was $600 \mathrm{~s}$, as shown in Fig. 4(b), there were few polishing flaws and white particles and ductile fractures appeared in some areas. These observations suggest that when the modification time is short, the oxide film is not substituted; and when the time is long, an excessive quantity of the compound is formed. For these reasons, it was determined that the best modification time was $600 \mathrm{~s}$.

Figure 5 presents the relationship between the bonding temperature and the tensile strength of the joint. To illustrate the effect of the modification, the results for a joint without modification are also shown. Although the tensile strength increased with bonding temperature independently of the surface modification, the tensile strength approached the base-metal strength at a bonding temperature about $40 \mathrm{~K}$ lower than that for the joint without modification. Moreover, fractures of the base metal in the joint occurred under the following conditions: $T=433 \mathrm{~K}$ with surface modification and $T=473 \mathrm{~K}$ without surface modification.

The fractured surfaces of the joints after the tensile test are shown in Figs. 6 and 7. At a bonding temperature of $433 \mathrm{~K}$ without surface modification, as shown in Fig. 6, polishing flaws were observed on the fractured surface of the copper side. These flaws were transferred to the fractured surface of the tin side. This observation suggests that close contact was achieved. As the bonding temperature increased fewer polishing flaws were observed, and the fractured surface was covered with accretions. Energy-dispersive X-ray spectrometry (EDX) analysis of the distribution of copper on the fractured surface of the tin side detected a small amount of copper at a bonding temperature of $433 \mathrm{~K}$. As the bonding temperature increased, copper was detected on the entire area of the fractured surface. It is thought that mutual diffusion occurs as a result of the destruction of both oxide films (copper and tin) at the convexity of the copper's surface. Moreover, mutual diffusion does not occur at the concavity of the copper's surface so both oxide films remain, because copper has been detected like the line at a bonding temperature of $453 \mathrm{~K}$. It is thought that the tensile strength of the joint increased since an interface was formed accompanied by the diffusion of copper and tin atoms. It is however uncertain whether it is a compound kept stoichiometric 


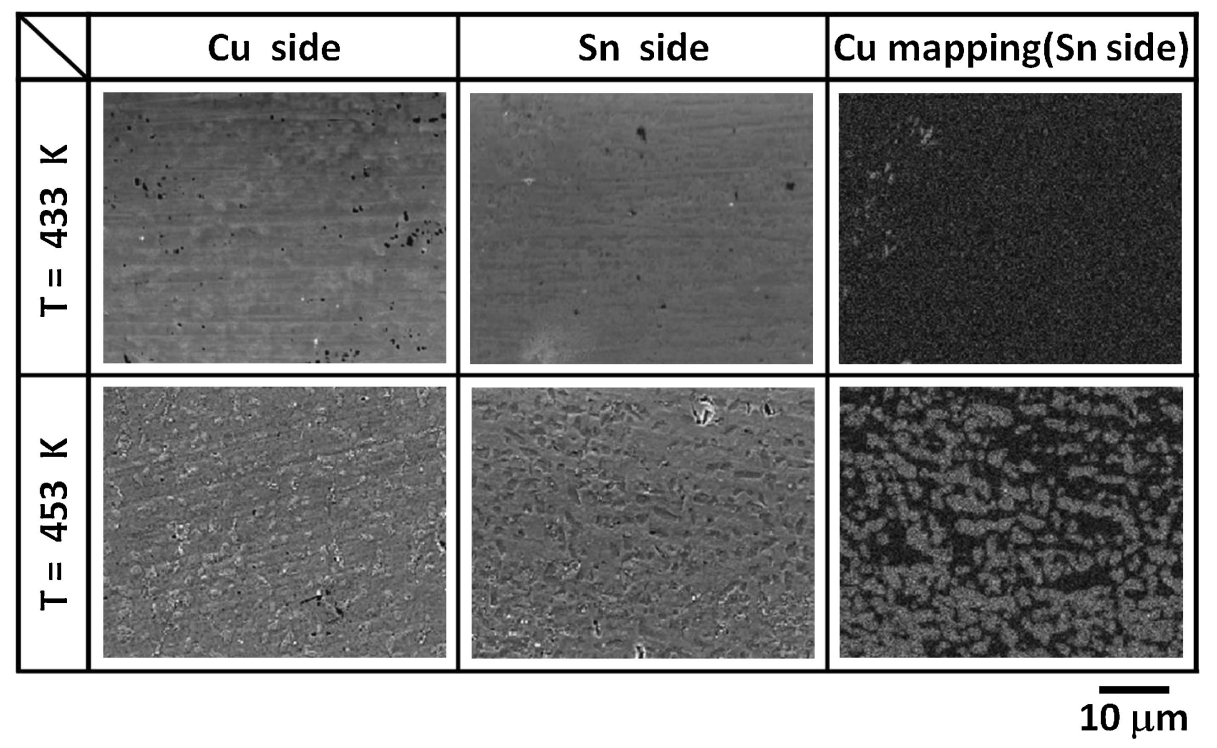

Fig. 6 SEM micrographs and EDX analysis of fractured surfaces of joints after tensile test (without surface modification).

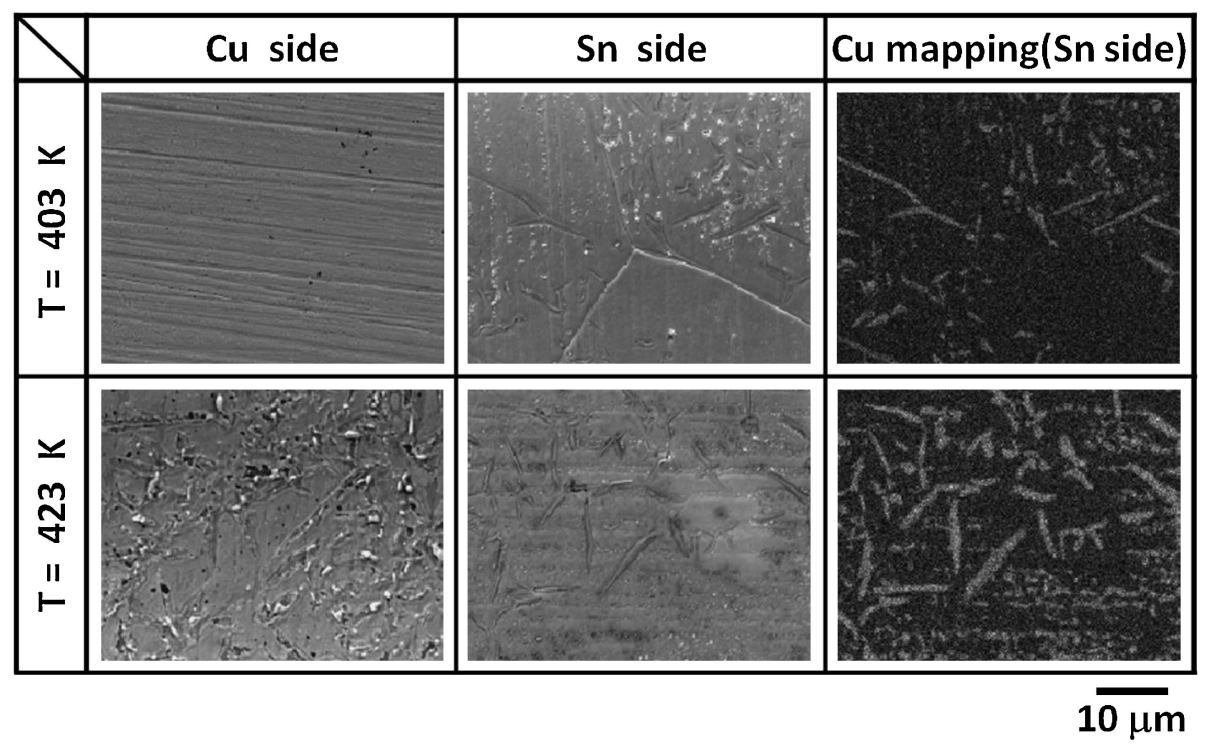

Fig. 7 SEM micrographs and EDX analysis of fractured surfaces of joints after tensile test (with surface modification).

proportion, such as $\mathrm{Cu}_{3} \mathrm{Sn}$ and $\mathrm{Cu}_{6} \mathrm{Sn}_{5}$, in the area where a large amount of copper was detected on the fractured surface of the tin side.

When surface modification was applied, as shown in Fig. 7, belt-like inclusions of $10 \mu \mathrm{m}$ or less in length and about $1 \mu \mathrm{m}$ in width were observed on the fractured surface of the tin side at a bonding temperature of $403 \mathrm{~K}$. These inclusions are thought to be a corrosion product of the tin produced by the formic-acid surface modification as described later. Polishing flaws were clearly observed on the fractured surface of the copper side but only rarely on the tin side. Therefore, it is hypothesized that the tensile strength of the joint reduced because tin transforms the plasticity only slightly and close contact with the copper was not achieved at a bonding temperature of $403 \mathrm{~K}$. As the bonding temperature increased, at the fractured surface on the copper side polishing flaws were rarely observed, and the fractured surface has changed into it which has the roughness.
The EDX analysis, as shown in Fig. 7, showed that copper was detected in the belt-like inclusions. As the bonding temperature increased, copper began to be detected not only in the inclusions but also in other areas along the polishing flaws. It is thought that there was no change in the ratio of the area made to stick because there was little change in the tin deformation under bonding when the bonding temperature changed from 403 to $423 \mathrm{~K}$. However, as the bonding temperature increased a large difference was observed in the amount of copper detected at the fractured surface of the tin side and the morphology of the fractured surface of the copper side. It is hypothesized that the occurrence of the corrosion product of tin and copper after the surface modification at about $423 \mathrm{~K}$ caused these differences. Moreover, the bonding temperature at which these changes occurred corresponded to that at which the tensile strength of the joint increased. The bonding temperature was about $30 \mathrm{~K}$ less than in the case without surface modification. Thus, it is hypothesized that 

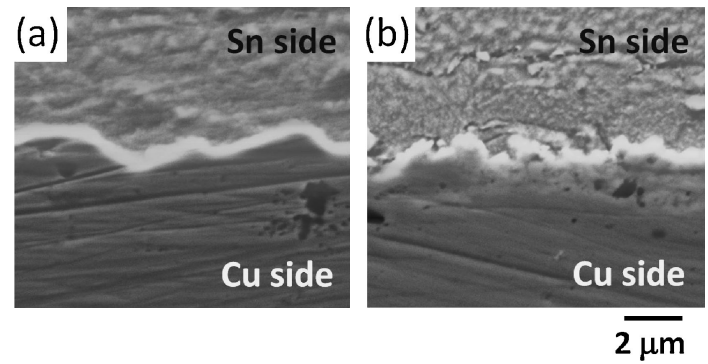

Fig. 8 SEM micrographs of bonded interfaces (without surface modification): (a) $T=433 \mathrm{~K}$ and (b) $T=453 \mathrm{~K}$.
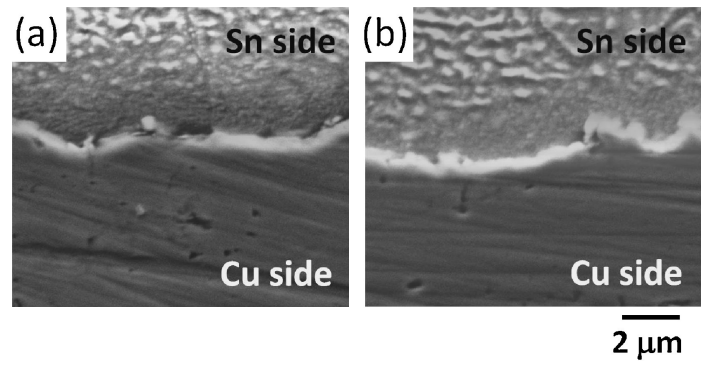

Fig. 9 SEM micrographs of bonded interfaces (with surface modification): (a) $T=403 \mathrm{~K}$ and (b) $T=413 \mathrm{~K}$.

high-tensile-strength joints were obtained at a lower bonding temperature with surface modification because the contact area between the tin and the copper was increased.

\subsection{Observation of bond interface}

Figures 8 and 9 show SEM micrographs of the tin/copper interface. When surface modification was not applied and the bonding temperature was $433 \mathrm{~K}$, as shown in Fig. 8(a), bonding defects such as voids and gaps were not observed although smooth ups and downs corresponding to the asperity of the grinding were observed. Moreover, it is understood that tin transforms the plasticity, and close contact to the surface of the copper is achieved at a bonding temperature of $433 \mathrm{~K}$ or higher. As the bonding temperature increased to $453 \mathrm{~K}$, the smooth ups and downs were not observed, and the interface changed so that limited roughness was observed (see Fig. 8(b)). Moreover, we observed a layer of about $2 \mu \mathrm{m}$ in width where the contrast was different from that of the other areas; this is thought to be a diffusion layer. Therefore, when formic-acid surface modification was not applied, high-tensile-strength joints were obtained by the formation of an interfacial structure with a diffusion layer of a few $\mu \mathrm{m}$ after close contact between the tin and copper was achieved.

When surface modification was applied and the bonding temperature was $403 \mathrm{~K}$, as shown in Fig. 9(a), voids of about $1 \mu \mathrm{m}$ in width were observed at the bond interface. Therefore, it is thought that the tensile strength of the joint was low and the fractures were brittle because close contact between the tin and copper was not achieved. At a bonding temperature of $423 \mathrm{~K}$, voids were not observed, and close contact was achieved in the observation area (see Fig. 9(b)). However, the layer where the contrast was different from that of the other areas, thought to be a diffusion layer, was not observed. Therefore, even if an interfacial structure with a diffusion

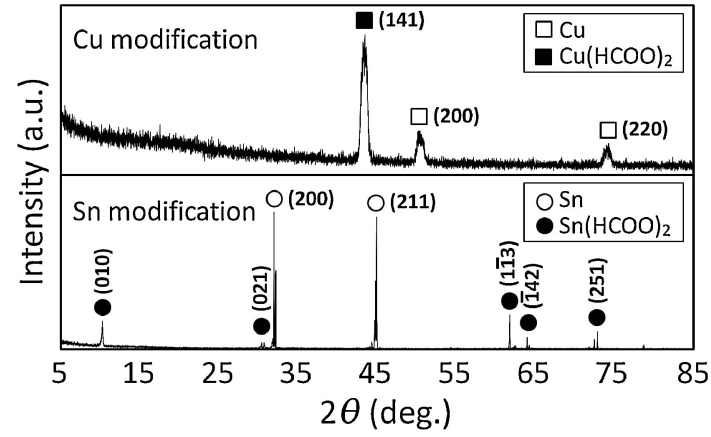

Fig. 10 X-ray diffraction patterns of surfaces of tin and copper modified by formic acid for about $700 \mathrm{~s}$.

layer was not formed, a high-tensile-strength joint was obtained when surface modification was applied.

\section{Discussion}

It is generally thought that tin and copper exposed to the atmosphere are immediately covered with an oxide film. It is known that tin(II) formate and copper(II) formate are formed by boiling the oxide film and the base metal with formic acid for a long time. ${ }^{9-11)}$ These formation reactions have the following reaction formulae $(X=\mathrm{Sn}, \mathrm{Cu})$ :

$$
\begin{aligned}
& \mathrm{X}+2 \mathrm{HCOOH} \rightarrow \mathrm{X}(\mathrm{HCOO})_{2}+\mathrm{H}_{2} \uparrow \\
& \mathrm{XO}+2 \mathrm{HCOOH} \rightarrow \mathrm{X}(\mathrm{HCOO})_{2}+\mathrm{H}_{2} \mathrm{O} \uparrow \\
& \mathrm{XO}_{2}+2 \mathrm{HCOOH} \rightarrow \mathrm{X}(\mathrm{HCOO})_{2}+\mathrm{H}_{2} \uparrow+\mathrm{O}_{2} \uparrow
\end{aligned}
$$

Therefore, it is thought that at least $\mathrm{Sn}(\mathrm{HCOO})_{2}$ and $\mathrm{Cu}(\mathrm{HCOO})_{2}$ were formed on the surface layer when surface modification was applied. The modification specified by reaction formulae (1)-(3) is supported by the analysis of the XRD patterns from the surface with surface modification applied (see Fig. 10). Moreover, it is known that at about $425 \mathrm{~K}$ tin(II) formate undergoes an exothermic decomposition reaction, ${ }^{9)}$ and carbon dioxide and formaldehyde as well as tin oxide are generated. ${ }^{12)}$ In fact, when solid-state bonding of tin was performed, tin(II) formate cohered while decomposing and contributed to the generation of metallic tin. ${ }^{9}$ On the other hand, it is known that at about $413 \mathrm{~K}$ copper(II) formate undergoes an exothermic decomposition reaction, as shown by following reaction formula, and metallic copper is generated: ${ }^{13)}$

$$
\mathrm{Cu}(\mathrm{HCOO})_{2} \rightarrow \mathrm{Cu}+\mathrm{H}_{2}+2 \mathrm{CO}_{2}
$$

It is therefore thought that a high-tensile-strength joint was obtained at a lower bonding temperature with surface modification because tin(II) formate and copper(II) formate at the bond interface underwent a decomposition reaction after close contact between the tin and copper was achieved.

\section{Conclusions}

(1) When surface modification is applied, the tensile strength increases with an increase in bonding temperature to $403 \mathrm{~K}$, and a joint is broken in the base metal at $433 \mathrm{~K}$. This tendency is observed at a bonding temperature about $40 \mathrm{~K}$ lower than that for a joint without surface modification. 
(2) When surface modification is not applied it is understood that, as the bonding temperature rises, the oxide film is destroyed by the improved plastic deformability of the tin. Thus, the tensile strength of the joint is increased.

(3) From the XRD analysis it is understood that formate, for which the decomposition reaction occurs at a low temperature, is generated by surface modification on the surface of the tin and copper.

(4) When surface modification is applied, it is hypothesized that a high-tensile-strength joint is obtained at a low temperature because metallic tin and copper are exposed as a result of the decomposition of formate in the bond interface at a low temperature.

\section{Acknowledgements}

This study was supported by Grant-in-Aid for Scientific Research (c) (21560741) from Japan Society for the Promotion of Science (JSPS).

\section{REFERENCES}

1) M. Hizukuri, N. Watanabe and T. Asano: IEEE Trans. Comp. Packag. Manuf. Technol. A 19 (2001) 34-40.

2) N. Watanabe and T. Asano: Jpn. J. Appl. Phys. 42 (2003) 2193-2197.

3) K. Tanida, M. Umemoto, Y. Tomita, M. Tago, R. Kajiwara, Y. Akiyama and K. Takahashi: Jpn. J. Appl. Phys. 42 (2003) 2198-2203.

4) J. Lee, H. Kim and C. D. Yoo: J. Electron. Mater. 34 (2005) 96-102.

5) T. Imamura, E. Higurashi, T. Suga and R. Sawada: IEEJ Trans. Sens. Micromach. 128 (2008) 266-270.

6) E. Higurashi, T. Imamura, T. Suga and R. Sawada: IEEE Photon. Tech. Lett. 19 (2007) 1994-1996.

7) A. Shigetou, T. Itoh and T. Suga: J. Mater. Sci. 40 (2005) 3149-3154.

8) Q. Wang, N. Hosoda, T. Itoh and T. Suga: Microelect. Reliab. 43 (2003) 751-756.

9) S. Koyama and I. Oya: J. Japan Inst. Metals. 73 (2009) 809-815.

10) S. J. Harrington, K. V. Kilway, D.-M. Zhu, J. M. Phillips and F. M. Leibsle: Surf. Sci. 600 (2006) 1193-1200.

11) S. Poulston, R. P. Holroyd, M. Bowker, S. F. Parker and P. C. H. Mitchell: Surf. Sci. 402-404 (1998) 599-603.

12) S. Yuji and K. Kimura: Muki Kagaku Zensyo VII-1-1 Suzu, (Maruzen, 1963) p. 360.

13) M. A. Mohamed, A. K. Galwey and S. A. Halawy: Thermochim. Acta 411 (2004) 13-20. 